\title{
POPULATION VIABILITY ANALYSIS FOR RED-COCKADED WOODPECKERS USING AN INDIVIDUAL-BASED MODEL
}

\author{
Jeffrey R. Walters,,$^{1,3}$ Larry B. Crowder, ${ }^{2}$ And Jeffery A. Priddy ${ }^{2}$ \\ ${ }^{1}$ Department of Biology, Virginia Polytechnic Institute and State University, Blacksburg, Virginia 24061-0406 USA \\ ${ }^{2}$ Duke University, Nicholas School of the Environment, Marine Laboratory, 135 Duke Marine Laboratory Road, \\ Beaufort, North Carolina 28516-9712 USA
}

\begin{abstract}
Red-cockaded Woodpeckers (Picoides borealis) are distributed in the southeastern United States among closed populations whose maximum size is limited. Previous population viability analyses for this species have been confined to examination of threats posed by catastrophes and loss of genetic variability, because of the lack of demographic models that incorporate the extreme spatial constraints on dispersal that characterize this species. We used a spatially explicit, individual-based simulation model to assess the vulnerability of Red-cockaded Woodpecker populations to demographic and environmental stochasticity. Vulnerability to these threats was relatively low, because the presence of a substantial nonbreeding class (i.e., helpers) ameliorated the impact of stochastic variation in mortality and reproduction on the size of the breeding population. Because dispersal of helpers is spatially restricted, this effect was most pronounced when territories were aggregated or at high densities. Populations of 250 and 500 territories were stable regardless of the level of territory aggregation at the densities examined, whereas populations of 25 , 49 , and 100 territories ranged from rapidly declining to stable, depending on territory density and level of aggregation. Techniques that enable managers to maintain existing territories and create new ones are well established for this species. Thus managers may reasonably expect to maintain even small populations of Red-cockaded Woodpeckers by increasing the density, level of aggregation, and number of territories.

Key words: cooperative breeding; demographic stochasticity; environmental stochasticity; individual-based model; management; Picoides borealis; population viability analysis; Red-cockaded Woodpecker; spatially explicit model.
\end{abstract}

\section{INTRODUCTION}

The relative viability of animal populations is a critical conservation issue. The USDA Forest Service has a legal mandate to preserve viable populations of vertebrate species, and impacts on viability are commonly an issue in decisions made by the U.S. Fish and Wildlife Service about the degree to which proposed actions jeopardize populations of species protected under the Endangered Species Act. Managers are concerned with the relative ability of alternative management actions to promote viability of populations on the lands for which they are responsible. Conservationists are concerned with the threats to viability posed by global habitat loss and fragmentation. Lacking sufficient relevant empirical data, viability usually is evaluated through mathematical modeling, a process known as population viability analysis, or PVA (Boyce 1992, Beissinger and Westphal 1998).

The Red-cockaded Woodpecker (Picoides borealis) is an endangered species endemic to pine habitats of the southeastern United States. It is well studied, being the subject of three symposia (Thompson 1971, Wood

Manuscript received 30 June 2000; revised 9 February 2001; accepted 14 February 2001; final version received 19 March 2001.

${ }^{3}$ E-mail: jrwalt@vt.edu
1983, Kulhavy et al. 1995), several review articles (e.g., Walters 1990, Jackson 1994), and numerous other publications. It is an unusual species, in that it is a cooperative breeder and excavates cavities for roosting and nesting in living pine trees. Its biology generally is well known, and management needs are well understood in comparison to those of other endangered species (Walters 1991, Jackson 1994, Conner et al. 2001). In contrast, assessment of the viability of Redcockaded Woodpecker populations is deficient relative to work on other endangered species.

The viability assessment paradigm is particularly appropriate for the Red-cockaded Woodpecker because of its space requirements and distribution. Family groups occupy permanent territories 50-100 ha in size (Walters 1990, Jackson 1994). The species is highly habitat specific, and habitat loss has produced a highly discontinuous distribution of the species across the southeastern United States (USFWS 1985, James 1995). Thus the species exists largely in closed populations whose maximum size is limited, which is the population structure to which viability analysis is most relevant.

Populations face four threats to their persistence: demographic stochasticity, environmental stochasticity, natural catastrophes, and genetic uncertainty (Shaffer 1981, 1987). The current recovery plan for the Red- 
cockaded Woodpecker (USFWS 1985) attempts to address the latter two threats, and subsequent work has improved on those attempts. Hurricanes are the primary catastrophic threat to Red-cockaded Woodpecker populations, but their effects can be minimized through management, specifically construction of artificial cavities (Copeyon 1990, Allen 1991, Copeyon et al. 1991) to replace cavities lost to storm damage (Watson et al. 1995). Methods for calculating the rate of loss of genetic variation have been developed (Reed et al. 1993) to replace the primitive methods used in the recovery plan (USFWS 1985). However, translating rates of loss of genetic variation into reductions in viability remains problematic (Lande 1988, 1995, Reed et al. 1993).

Conspicuously lacking are attempts to assess vulnerability to demographic and environmental stochasticity, the cornerstone of most viability analyses (e.g., Lacy and Clark 1990, Ryan et al. 1993, Beissinger 1995). Models of Red-cockaded Woodpecker demography exist (Heppell et al. 1994, Maguire et al. 1995), but the utility of these models in simulating population dynamics is limited because they do not incorporate the extreme spatial constraints on dispersal that characterize this species. Many males and some females, instead of dispersing in their first year to acquire breeding positions, remain on their natal territory as nonbreeding helpers (Ligon 1970, Lennartz et al. 1987, Walters et al. 1988, Walters 1990). Helpers eventually become breeders by inheriting a breeding position on the natal territory or dispersing to fill a breeding vacancy, but they only compete for breeding vacancies in the immediate vicinity of their home territory (Walters et al. 1988, Daniels 1997). Helpers represent a pool of replacement breeders and thus can act as a buffer between breeder mortality and population productivity, but only if they are within dispersal range of the territories on which breeders perish.

Vucetich and Creel (1999) advocate the use of complex models when there are large effects of social structure on population dynamics (see also Boyce 1992). Red-cockaded Woodpeckers clearly meet this criterion. Previous population models for Red-cockaded Woodpeckers are deterministic (Heppell et al. 1994) or stochastic (Maguire et al. 1995) stage-based matrix models. They represent sophisticated versions of the types of single-sex, single-population model most commonly used in population viability analysis (Beissinger and Westphal 1998). These Red-cockaded Woodpecker models have yielded important insights, but their authors, too, have advocated the use of more complex models to simulate population dynamics, specifically spatially explicit, two-sex models (Heppell et al. 1994, Maguire et al. 1995).

Spatially explicit, individual-based models, because they track the performance and fate of individual organisms (Judson 1994) and their locations (Dunning et al. 1995), can incorporate constraints on movement. Previously, we described such a model for Red-cock- aded Woodpeckers and used it to show that the buffering effect of helpers was sufficient to prevent demographic stochasticity from producing fluctuations in the size of the breeding population, provided territories were sufficiently aggregated (Letcher et al. 1998). This result is of limited significance to conservation, because demographic stochasticity is a relatively minor source of variability compared to environmental stochasticity. Here we assess the power and consequences of the buffering effect of helpers under more realistic conditions, by considering environmental stochasticity as well as demographic stochasticity in a formal viability analysis. Specifically, we examine effects of territory number and territory distribution on viability within the range of population densities currently characterizing Red-cockaded Woodpeckers.

\section{Methods}

\section{Model structure}

A major limitation of complex simulation models is the amount of data required for parameter estimation (Murdoch et al. 1992, Conroy et al. 1995, Beissinger and Westphal 1998). Fortunately, extensive, detailed demographic data for Red-cockaded Woodpeckers were available from $15 \mathrm{yr}$ of study of $>200$ groups of color-marked birds in the North Carolina Sandhills (Carter et al. 1983, Walters et al. 1988, Daniels 1997). These data drove the construction of our model and, to a large extent, dictated its structure.

The model is described in detail in Letcher et al. (1998). Briefly, the landscape in the model consists of breeding territories and nonbreeding space that the birds must cross to find the territories. In this species, territories may be occupied for decades (Doerr et al. 1989), and new territories are created primarily through the process of budding, in which one territory (and its cavities) is divided into two (Hooper 1983). In the model, accordingly, territory locations are fixed, but territories are lost if unoccupied for more than five consecutive years. New territories are created through budding and each existing territory has a probability of $1 \%$ of producing a bud each year. However, a territory can bud only if sufficient, unoccupied space is available in its vicinity. Thus the effective budding rate is $<1 \%$ at high densities. Budding rates reported from natural populations vary from near zero to $2 \%$ (Doerr et al. 1989, Conner et al. 2001).

The model is configured for both males and females: female fledglings disperse in their first year, whereas male fledglings may either disperse or become helpers. In the model, dispersing fledglings move in a random direction and continue in that direction at a specified rate until they die, obtain a breeding position, or leave the population. At each time step, they compete for any breeding vacancy within $3 \mathrm{~km}$ of their current position. Males may compete for both breeding vacancies and empty territories, but females may only move into ter- 
ritories that contain a male. Helpers do not change status or location until they die or fill a breeding vacancy. The oldest helper inherits breeding status if the breeder on its territory dies and helpers compete for any breeding vacancies within $3 \mathrm{~km}$ of their home territory. The probability of mortality of each individual depends on its status. Mortality rates and helper dispersal behavior are well documented (Walters et al. 1988, 1992, Daniels 1997), as are dispersal probabilities and dispersal distances of fledglings (Walters et al. 1988, Daniels and Walters 2000), but the behavior of fledglings while dispersing is not.

The number of fledglings produced on each territory each breeding season is a function of breeder age and number of helpers present. In this species, young birds (i.e., $<4$ yr old) are less productive than older ones (Walters et al. 1988, 1992, Walters 1990), and helpers increase the productivity of their group (Lennartz et al. 1987, Walters 1990, Heppell et al. 1994).

\section{Initial conditions}

For each model run, the landscape contained a predetermined number and density of territories arranged according to a predetermined level of clumping. The territories were added as circles that ranged in radius from 0.3 to $0.5 \mathrm{~km}$, with the final size being dependent on territory density (for additional details, see Letcher et al. 1998). The same initial conditions were applied randomly to each territory. Each territory had a $90 \%$ chance of beginning with a breeding pair, and territories without a breeding pair contained a solitary male. A number of helpers equal to one-half the number of territories was added randomly to the territories with pairs, so that about one-half of the territories had no helpers, and a few had more than one. The ages of the birds also were assigned randomly, but from a distribution designed to reproduce the age distribution of birds observed in the North Carolina Sandhills population in 1991, a typical year (J. R. Walters, J. H. Carter III, and P. D. Doerr, unpublished data). These initial conditions were independently applied to each run of each scenario. Thus variation among replicates was due to variation in the initial population, as well as variation in simulation dynamics.

Demographic stochasticity was incorporated into the simulations by applying to each individual annual survival probabilities, annual status transition probabilities of male fledglings, and probabilities of producing different numbers of fledglings. This was accomplished by drawing a deviate from a random uniform distribution and determining whether or not the deviate was less than the appropriate probability value. Environmental stochasticity was incorporated by varying survival probabilities and probabilities of producing different numbers of fledglings each year. This was accomplished by determining the variance among years in these parameters across $14 \mathrm{yr}$ of data from the North Carolina Sandhills, and then drawing randomly each year from the resulting distribution to determine that year's probability value. This procedure was applied independently to each parameter, as we found no covariance in survival probabilities among status classes or between survival and productivity in the North Carolina Sandhills data.

\section{Simulation scenarios}

We ran 100 replicates, each of $100 \mathrm{yr}$ duration, for each simulation scenario. We first simulated populations of five different sizes $(25,49,100,250$, and 500 initial territories), each at two different levels of aggregation, on a landscape $32 \times 24 \mathrm{~km}$ in size. The landscape size was chosen to match the range of densities observed among existing populations. Specifically, the 49 and 100 territory scenarios match current densities of two coastal North Carolina populations and the 500 territory scenario corresponds to the recommended density in recent management guidelines. The two levels of aggregation span the range of variability in clumping among real populations.

A random distribution of territories on $x-y$ axes constituted one level of aggregation. We used the $k$ parameter of the negative binomial distribution to generate the second level of aggregation. For a particular number of territories distributed across the landscape, we determined the $k$ values when territories were minimally (i.e., randomly distributed, maximum $k$ ) aggregated and maximally (i.e., aggregated in one large patch, minimum $k$ ) aggregated. To create the second level of aggregation, we selected a $k$ value that was $25 \%$ of the distance between $\log k_{\min }$ and $\log k_{\max }$. We then generated spatial distributions of territories using those $25 \% k$ values, which represent a fairly high degree of clumping (Fig. 1).

In the first set of simulations, population size and territory density covary. To examine the effects of density independent of the effects of population size and aggregation, we conducted a second set of simulations. In the second set, we simulated population dynamics of the smaller populations (25, 49, and 100 territories) at each of the densities characterizing the larger populations (250 and 500 territories) in the first set of simulations. This was accomplished by changing the size of the landscape to produce the required overall density (Fig. 1). In the second set of simulations, territories were randomly distributed on the landscapes (i.e., the maximum $k$ value was used).

For each simulation scenario, we measured the mean and variance among the 100 replicates in annual population growth rate and the percentage of the initial territories remaining after 100 yr. The latter was calculated as the number of surviving original territories plus the number of surviving territories formed by budding, divided by the number of original territories. We also calculated the number of replicates in which extinction, defined as loss of all territories, occurred, and the mean and distribution of time to extinction. 


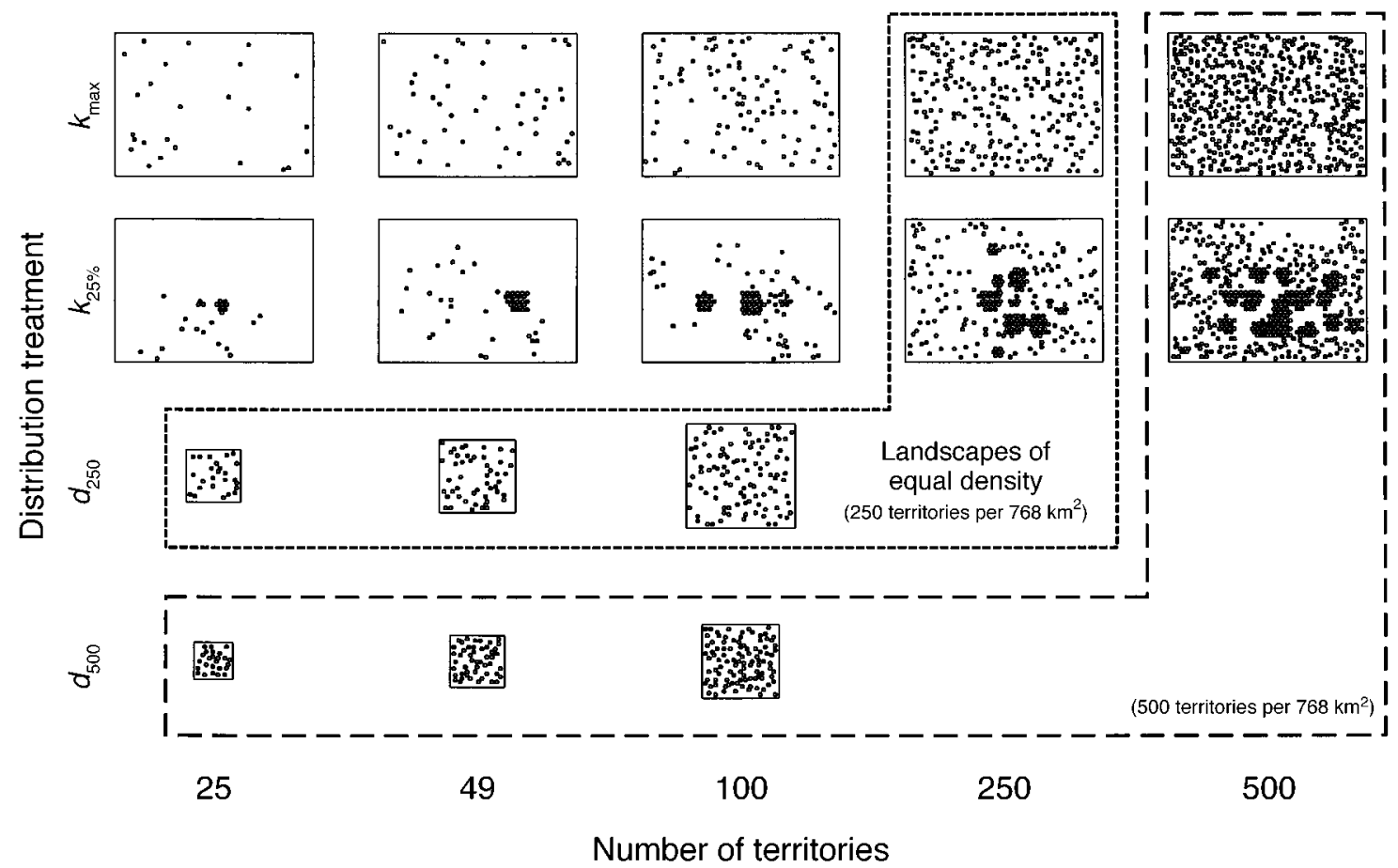

FIG. 1. Examples of the spatial arrangement of territories for each of the simulation scenarios. Dots represent territories. Distribution treatments are: $k_{\max }$, random distribution on a $768-\mathrm{km}^{2}$ landscape; $k_{25 \%}$, more aggregated than random distribution on a $768-\mathrm{km}^{2}$ landscape; $d_{250}$, random distribution at a density equivalent to 250 territories $/ \mathrm{km}^{2}$; and $d_{500}$, random distribution at a density equivalent to 500 territories $/ 768 \mathrm{~km}^{2}$. See Methods: Simulation scenarios.

\section{RESULTS}

Population growth rate varied with both territory number and territory distribution (Fig. 2). The mean growth rate was close to 1.0 for populations of 250 and 500 territories, for both levels of aggregation. Although the mean growth rate of populations of 25,49 , and 100 territories was $<1.0$, growth rate among these populations was highly dependent on the level of aggregation. For example, the mean growth rate of populations of 100 randomly distributed territories was less than the mean growth rate of populations of 50 more aggregated territories (Fig. 2). Population density also had a pronounced effect on population growth rate. Mean growth rates of small populations were considerably higher under both high-density conditions. In fact, the mean growth rate of populations of 100 reached 1.0 at the highest density (Fig. 3).

The average number of surviving territories after 100 yr was as high or higher than the initial number for populations of 250 and 500 initial territories at all densities, for populations of 100 initial territories at the two highest densities, and for populations of 50 initial territories at the highest density (Figs. 4 and 5). For populations of 25,49 , and 100 initial territories, initial population size, aggregation, and density all had pronounced effects on the average number of surviving territories.

No populations of 250 or 500 groups went extinct at either level of aggregation. For smaller populations, the number of simulations in which extinction occurred varied with population size, aggregation, and density (Table 1). All populations of 25 and 49 groups went extinct quickly at the lowest level of aggregation, but populations of these sizes survived much longer, sometimes for $100 \mathrm{yr}$, when density or aggregation was higher (Table 1, Fig. 6). Most populations of 100 groups went extinct at the lowest level of aggregation, whereas all survived at the highest density (Table 1).

\section{DISCUSSION}

\section{Effects of population size and spatial distribution}

Our simulations resulted in two major findings. First, distribution and density of territories have as large an effect on population behavior as population size, at least within a certain range of population sizes (i.e., fewer than 250 territories). Second, effects of environmental stochasticity are relatively small compared to those evident in viability analyses of other species (Beissinger 1995, Wisdom and Mills 1997, Beissinger and Westphal 1998); as a result, relatively small populations could be relatively stable. Indeed, the behavior of populations in this study was quite similar to that of comparable populations in a previous analysis in which only effects of demographic stochasticity were considered (Letcher et al. 1998). These results can be related to the buffering effect of helpers on population 


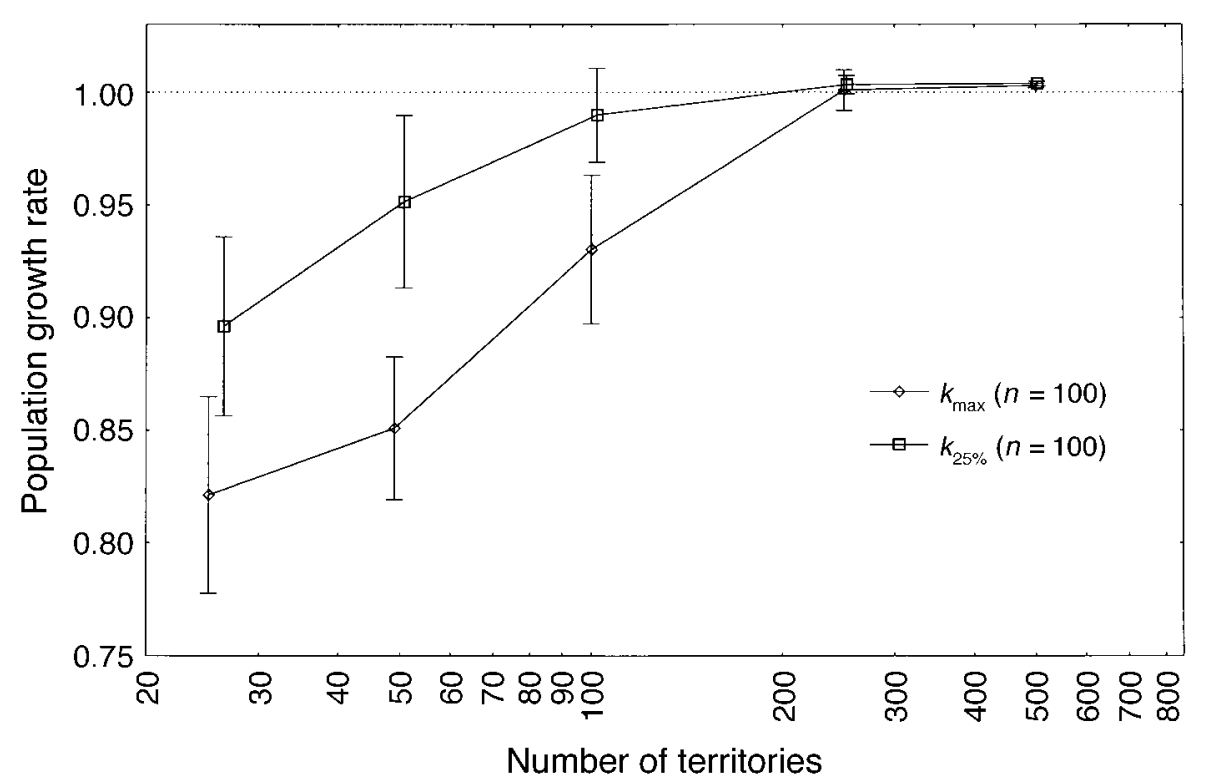

FIG. 2. Annual population growth rate as a function of number of territories and distribution. The mean and standard deviation among 100 replicates are indicated for each condition; $k_{\max }$ indicates random distribution of territories, and $k_{25 \%}$ a more aggregated distribution (see Methods: Simulation scenarios for additional description).

dynamics. The presence of a substantial nonbreeding class ameliorates the impact of stochastic variation in mortality and reproduction on the size of the breeding population. Such variation leads to fluctuations in the size of the helper class rather than to changes in the number of territories occupied. Evidently, the capacity of the helper class to absorb stochastic variation is sufficient to absorb not only demographic stochasticity, but also environmental stochasticity, at least down to a population size of 50 groups. However, the buffer effect depends on territories being within the dispersal range of helpers of one another. Hence its capacity is determined by population density and aggregation, as well as size. Vucetich et al. (1997) describe a similar

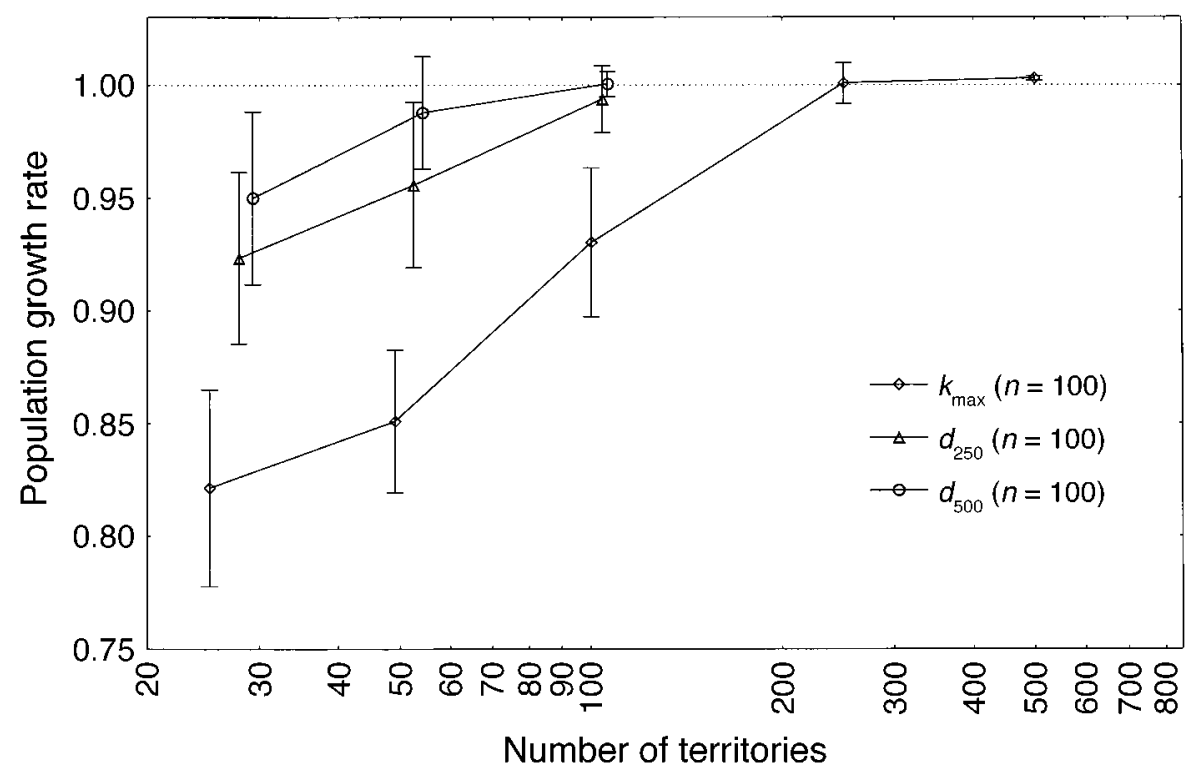

FIG. 3. Annual population growth rate as a function of territory number and density. The mean and standard deviation among 100 replicates are indicated for each condition. The lower density $\left(d_{250}\right)$ corresponds to 3.26 territories $/ \mathrm{km}^{2}$, the density of 250 randomly distributed territories in the first set of simulations $\left(k_{\max }\right.$ in Fig. 2). The higher density $\left(d_{500}\right)$ corresponds to 6.51 territories $/ \mathrm{km}^{2}$, the density of 500 randomly distributed territories in the first set of simulations. Results for randomly distributed territories at the various densities examined in the first set of simulations are shown for comparative purposes $\left(k_{\max }\right)$. 


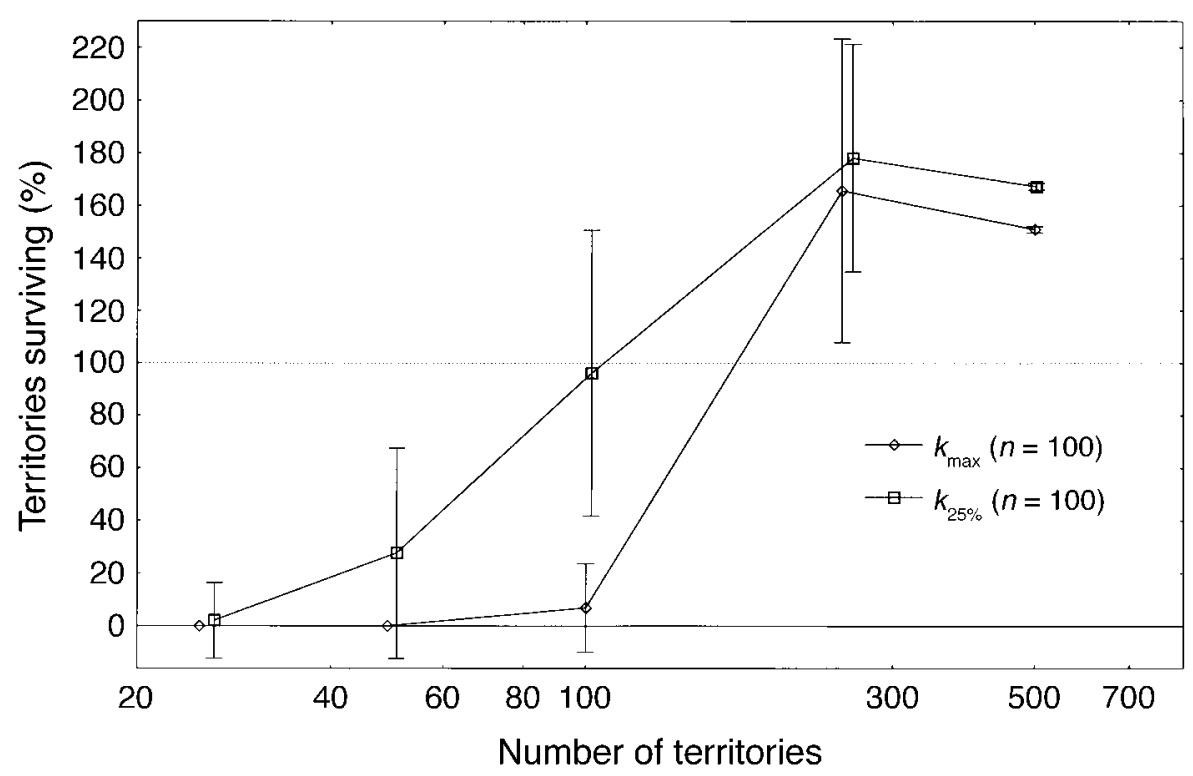

FIG. 4. Percentage of initial territories surviving after $100 \mathrm{yr}$ as a function of initial number of territories and distribution. The mean and standard deviation among 100 replicates are indicated for each condition; $k_{\max }$ indicates random distribution of territories, and $k_{25 \%}$ indicates a more aggregated distribution.

stabilizing effect due to the presence of a nonbreeding class in wolves (Canis lupus). Viability of small populations may generally be higher in species with complex social structures that include a large class of nonbreeding adults.

Regardless of the buffering effect of helpers, it appears that the magnitude of environmental stochasticity may be relatively small in this species, at least with respect to some aspects of demography. Red-cockaded Woodpeckers exhibit considerable annual variation in productivity, but relatively little in mortality. In the North Carolina Sandhills, mortality rates of a particular age-sex class vary over a range of $\sim 15 \%$ among years, and, except for the occasional unusual year, variation

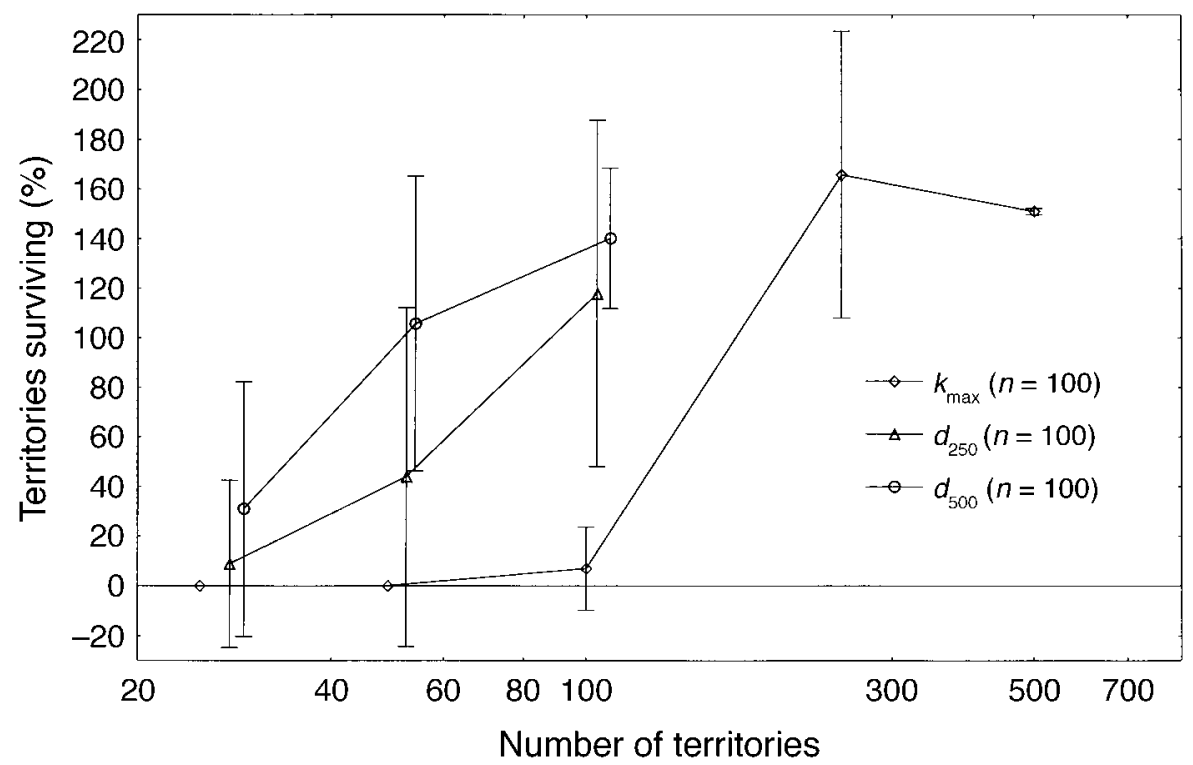

FIG. 5. Percentage of initial territories surviving after $100 \mathrm{yr}$ as a function of initial territory number and density. The mean and standard deviation among 100 replicates are indicated for each condition. The lower density $\left(d_{250}\right)$ corresponds to 3.26 territories $/ \mathrm{km}^{2}$, the density of 250 randomly distributed territories in the first set of simulations $\left(k_{\max }\right.$ in Fig. 4). The higher density $\left(d_{500}\right)$ corresponds to 6.51 territories $/ \mathrm{km}^{2}$, the density of 500 randomly distributed territories in the first set of simulations. Results for randomly distributed territories at the various densities examined in the first set of simulations are shown for comparative purposes $\left(k_{\max }\right)$. 
TABLE 1. Number of simulations out of 100 in which extinction of Red-cockaded Woodpecker populations occurred, and mean time to extinction as a function of territory number and distribution.

\begin{tabular}{cccc}
\hline \hline No. territories & Distribution $\dagger$ & $\begin{array}{c}\text { No. } \\
\text { extinctions }\end{array}$ & $\begin{array}{c}\text { Time to extinction } \\
\text { (yr) }(\text { mean } \pm 1 \text { SD) }\end{array}$ \\
\hline 25 & $k_{\max }$ & 100 & $24 \pm 6$ \\
25 & $k_{25 \%}$ & 95 & $44 \pm 18$ \\
25 & $d_{250}$ & 90 & $56 \pm 19$ \\
25 & $d_{500}$ & 66 & $66 \pm 20$ \\
49 & $k_{\max }$ & 100 & $33 \pm 9$ \\
49 & $k_{25 \%}$ & 53 & $67 \pm 18$ \\
49 & $d_{250}$ & 50 & $69 \pm 16$ \\
49 & $d_{500}$ & 15 & $77 \pm 15$ \\
100 & $k_{\max }$ & 74 & $68 \pm 16$ \\
100 & $k_{25 \%}$ & 7 & $84 \pm 12$ \\
100 & $d_{250}$ & 4 & \\
100 & $d_{500}$ & 0 & \\
250 & $k_{\max }$ & 0 & \\
250 & $k_{25 \%}$ & 0 & \\
500 & $k_{\max }$ & 0 & \\
500 & $k_{25 \%}$ & 0 & \\
\hline
\end{tabular}

$\dagger$ Here, $k_{\max }$ and $k_{25 \%}$ indicate degree of aggregation of territories, $k_{\max }$ representing a random distribution, and $k_{25 \%}$ a more aggregated than random distribution; $d_{250}$ and $d_{500}$ indicate territory density, corresponding to densities of 250 and 500 territories per $762 \mathrm{~km}^{2}$, respectively. See Methods: Simulation scenarios for details.

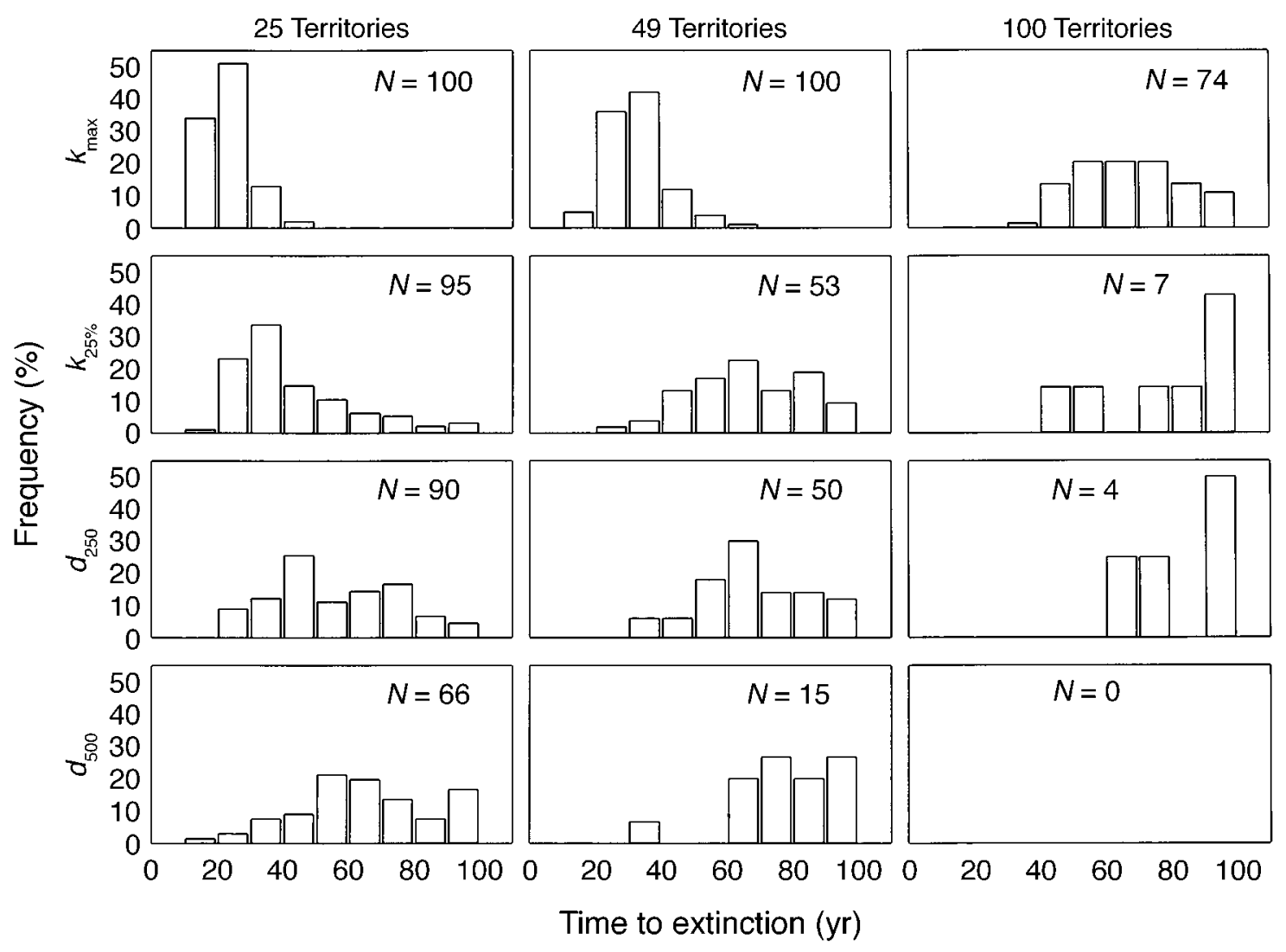

FIG. 6. Distribution of time to extinction for simulations in which extinction occurred as a function of number of territories and distribution, where $k_{\max }$ indicates random distribution of territories within a $32 \times 24 \mathrm{~km}$ landscape; $k_{25 \%}$, a more aggregated distribution within this same landscape; $d_{250}$, a density of 3.26 territories $/ \mathrm{km}^{2}$ (equivalent to $k_{\max }$ for 250 territories), and $d_{500}$, a density of 6.51 territories $/ \mathrm{km}^{2}$ (equivalent to $k_{\max }$ for 500 territories). 


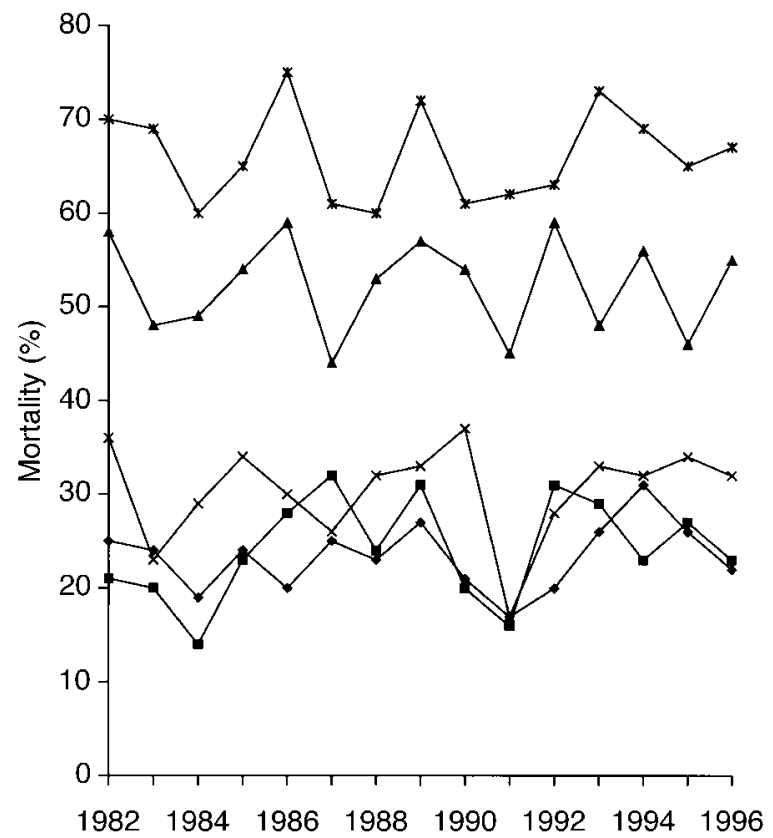

FIG. 7. Annual mortality rates for Red-cockaded Woodpeckers from various status classes in the North Carolina Sandhills, 1982-1996. Each value represents mortality from the breeding season indicated until the next; i.e., 1990 represents mortality between the 1990 and 1991 breeding seasons. Key to symbols (from bottom to top): squares represent helper males, diamonds are breeding males, $\times$ symbols are breeding females, triangles are fledgling males, and asterisks are fledgling females.

appears to be relatively uncorrelated among status classes (Fig. 7). The range of variation observed in the Sandhills (Fig. 7) is likely to encompass all but the most severe catastrophic events. When the Camp Lejeune population in coastal North Carolina was struck by two hurricanes between the 1996 and 1997 breeding seasons, mortality of breeding males that year was $29 \%$, compared to an average value over the previous $10 \mathrm{yr}$ of $18 \%$ (J. R. Walters, unpublished data). During that same year, mortality of helper males was $39 \%$ compared to an average value of $23 \%$, and that of breeding females was $31 \%$ compared to an average value of $24 \%$. Mortality of fledglings was not affected. Hurricane Hugo, however, caused mortality well beyond this range when it struck the population on the Francis Marion National Forest in 1989 (Hooper et al. 1990).

How realistic are the densities that we examine? We have been involved in field studies of Red-cockaded Woodpeckers at four locations in recent years: Eglin Air Force Base in the Florida panhandle; Croatan National Forest and Camp Lejeune Marine Base in coastal North Carolina; and the Sandhills population in southcentral North Carolina. The densities of the two coastal populations in North Carolina lie between those of our theoretical populations of 49 and 100, and these populations are between 49 and 100 territories in size. The densities of the other two populations lie between those of our theoretical populations of 100 and 250, and these populations are $\sim 250$ territories in size. Territories in the real populations are more aggregated than random because of the distribution of suitable habitat.

Densities of most existing populations fall within the range represented by our theoretical populations of 49250 , and their level of aggregation probably is comparable to our $k_{25 \%}$. Recommended densities in suitable habitat in current management documents correspond to populations of 475-950 territories on our $32 \times 24$ km landscape (USFWS 1985, USDA 1995, U.S. Army 1996). Our results suggest that even small populations (i.e., 25 territories) might be fairly persistent at these densities, but achieving these densities will be constrained by the proportion of suitable habitat in the total landscape. The higher density levels that we examined, however, should be achievable on most landscapes. These correspond to roughly one territory per 300 ha (our 250 territories) and one territory per 160 ha (our 500 territories).

Our population projections should not be taken literally until the model has been more thoroughly validated. The model is subject to a variety of inaccuracies that make it inappropriate to interpret our results in absolute terms. Some parameters may be inaccurate, notably dispersal speed and search range of fledglings. Considerable controversy exists over the sensitivity of spatially explicit models to errors in estimation of dispersal parameters (Wennergren et al. 1995, Ruckelshaus et al. 1997, 1999, Mooij and DeAngelis 1999, South 1999). Even those parameter values based on sufficient data come from a single population and thus may not be representative of all populations. Mortality rates are known to be lower in coastal North Carolina (J. R. Walters, unpublished data) and central Florida (DeLotelle et al. 1995) than in the North Carolina Sandhills, for example. Especially important in this respect is helper dispersal. Although helper search range is well documented for the North Carolina Sandhills (Walters et al. 1988, Daniels 1997), and helper life history is constant across populations, it is not known whether helper search range changes with population density. If it increases when population density is low, as seems likely, stability will decrease less, with decreasing density, than our simulations suggest. Fortunately, model performance is not highly sensitive to any of these parameters (Letcher et al. 1998). Therefore, we believe that the strong effects of density and aggregation evident in our results are real.

\section{Implications for management}

The obvious implication of these findings is that management actions that increase the aggregation and density of territories of this endangered species will be beneficial; those that increase the isolation of territories will be harmful. Although this may be viewed as a general principle, the benefits of improved spatial structure will only be manifest when the assumptions 
of our analyses are met. Most importantly, we assume that territories will not be lost to habitat degradation, and that vital rates are not depressed by adverse anthropogenic factors. That is, we assume that the important conservation problems currently are those inherent to small, isolated populations (i.e., the small population paradigm; Caughley 1994) rather than the environmental problems that caused the species to become endangered (i.e., the declining population paradigm; Caughley 1994). This may seem a questionable approach for an endangered species, but in this case, there is ample justification. As recently as the late 1980s, most populations of Red-cockaded Woodpeckers were declining and the healthiest ones, with one exception (Hooper et al. 1991), were stable rather than increasing (Conner and Rudolph 1989, Costa and Escano 1989). Clearly, the declining population paradigm was the appropriate one in this era. However, breakthroughs in research and management provided an understanding of the factors driving populations to extinction and the means to combat them (Walters 1991, Conner et al. 2001). In the 1990s, well-managed populations, even small ones, have increased (Franzreb 1997, Conner et al. 2001). Our results apply to these well-managed populations. Where the critical environmental problems have yet to be addressed, populations will perform more poorly than suggested by our model projections because of violations of our assumptions about habitat quality and vital rates.

Especially relevant among the current management tools are prescribed growing-season fire to control the hardwood midstory, and construction of artificial cavities to replace cavities lost to wind damage, fire, lightning strikes, and other forces. In combination, these tools can eliminate the forms of habitat degradation that cause territories to be abandoned (Walters 1991). Also, construction of artificial cavities in unoccupied areas stimulates formation of new groups on new territories (Copeyon et al. 1991). Population growth rates of $5-10 \%$ can be achieved with artificial cavity construction, whereas growth rates through natural processes are only 1-2\% (Conner et al. 2001). Thus populations may perform better than our model projections where artificial cavity construction is employed effectively. This technique is ideal for improving the aggregation and density of territories, and thereby also improving population behavior.

One possible concern in increasing the aggregation of territories is that vulnerability to catastrophe may increase. Hurricanes are the only significant catastrophic threat to Red-cockaded Woodpecker populations, but the threat is serious (Hooper et al. 1990, Hooper and McAdie 1995). In fact, Hooper and McAdie (1995) recommend against aggregating groups to reduce hurricane impacts. However, the scale of hurricane damage is much larger than the scale at which aggregation affects population behavior. Whether woodpecker territories are aggregated or scattered within a hurricane's path will have little effect on the damage sustained. More important are managing habitat to reduce vulnerability to wind damage (Hooper and McAdie 1995) and countering any losses of cavity trees by constructing artificial cavities. Through these means, impacts of hurricanes on Red-cockaded Woodpecker populations have been minimized in recent years (Conner et al. 2001). We conclude that the benefits of territory aggregation to population dynamics greatly outweigh any costs due to increased vulnerability to catastrophe.

The relative stability in our simulations of fairly small populations with favorable spatial distributions, coupled with the existence of management tools that can increase stability, offer hope that even small populations of Red-cockaded Woodpeckers can be maintained. There is empirical evidence that this hope might be realistic. Although many small populations have declined, some isolated populations of only 25 or even 10 territories have been remarkably persistent (James 1995). Our assessment of these data is that persistence is associated with high levels of territory aggregation.

Additional empirical evidence of the importance of spatial distribution of territories is emerging from wellmanaged populations. Where habitat is fragmented and, as a result, population density is low, populations tend to decline (Conner and Rudolph 1991). In large populations, territories tend to be lost at the edges of the population and gained (through budding) in the center. This has occurred, for example, at Eglin Air Force Base in Florida (J. R. Walters and K. E. Gault, unpublished data) and in the North Carolina Sandhills (J. H. Carter III, J. R. Walters, and P. D. Doerr, unpublished data) in recent years.

\section{Population viability standards}

Regardless of its advisability in theory, in practice, agencies routinely set population size objectives based on assessments of viability. Current management guidelines for the Red-cockaded Woodpecker stipulate that a population size of $\sim 400$ territories is required for viability (USDA 1995, U.S. Army 1996). This standard is based solely on projected rates of loss of genetic variability (USFWS 1985, Reed et al. 1993). The basis of such a criterion is sufficiently suspect (Lande 1988, 1995, Reed et al. 1993) that maintaining sufficiently large, closed populations should be abandoned in favor of other means to maintain genetic variability, such as translocation of individuals between populations. Translocation techniques are well developed for this species (DeFazio et al. 1987, Rudolph et al. 1992). Demographic stability is much more critical, but no demographic viability standard has been proposed previously, because of the limitations of previous models in projecting population dynamics. Our results do not suggest a strict population size standard. They do suggest that it may be possible to maintain populations much smaller than the previous standard, and that in- 
creasing territory aggregation, density, and number are all important.

Only a few Red-cockaded Woodpecker populations are as large as the largest size classes (250-500 territories) that we analyzed, but many are of comparable size to the smaller size classes (25-250 territories) that we considered, and some are even smaller (James 1995). Our results suggest that the largest populations (i.e., 250-500 territories) can readily be maintained and that those of intermediate size (i.e., 49-250 territories) might be as well, if densities and levels of aggregation are favorable. In some cases, but perhaps not all, judicious management will be required to achieve stability. The critical point is that, over a wide range of population sizes and realistic levels of aggregation and density, projected population growth rates remained within the range in which losses can reasonably be countered by available management techniques. The size at which populations performed well over a range of reasonable densities, 100 territories, is considerably smaller than is typical of animal species. This provides reason to be optimistic about recovery efforts for the species, considering that large populations (i.e., 500 or even 250 territories) are not achievable on many management units.

Very small populations (i.e., $\leq 25$ territories) present a more difficult problem. Many will probably decline faster than can be counteracted by management. Still, they may not be doomed if high levels of aggregation can be achieved. Indeed, when we simulated very small populations, we found that even populations of as few as 10 territories could be sufficiently stable to be maintained through management if territories were maximally aggregated (L. B. Crowder, J. A. Priddy, and J. $\mathrm{R}$. Walters, unpublished report). Management of isolated groups seems a poor investment, but management of small aggregations of groups may not be.

In conclusion, our results suggest that populations of Red-cockaded Woodpeckers are less prone to the stochastic fluctuations in size that plague efforts to preserve isolated populations of many other species. This provides managers with additional incentive to invest in their populations, however small, as it increases the chances that their efforts will produce demonstrable benefits. Seldom does the fate of a species depend so much on how effectively appropriate management is implemented.

\section{ACKNOWLEDGMENTS}

We thank Selina Heppell and Karin Schiegg for helpful discussion, and Benjamin Letcher for his initial work on the simulation model. We also acknowledge Jay Carter, Phillip Doerr, and Kerry Brust, whose ongoing efforts have contributed greatly to the production of the North Carolina Sandhills data set on which we have relied in our modeling efforts.

\section{Literature Cited}

Allen, D. H. 1991. An insert technique for constructing artificial red-cockaded woodpecker cavities. USDA Forest Service General Technical Report SE-73.
Beissinger, S. R. 1995. Modeling extinction in periodic environments: everglades water levels and Snail Kite population viability. Ecological Applications 5:618-631.

Beissinger, S. R., and M. I. Westphal. 1998. On the use of demographic models of population viability in endangered species management. Journal of Wildlife Management 62: 821-841.

Boyce, M. S. 1992. Population viability analysis. Annual Review of Ecology and Systematics 23:481-506.

Carter, J. H., III, R. T. Stamps, and P. D. Doerr. 1983. Status of the red-cockaded woodpecker in the North Carolina Sandhills. Pages 24-29 in D. A. Wood, editor. Red-cockaded woodpecker Symposium II. Florida Game and Freshwater Fishery Commission and U.S. Fish and Wildlife Service, Atlanta, Georgia, USA.

Caughley, G. 1994. Directions in conservation biology. Journal of Animal Ecology 63:215-244.

Conner, R. N., and D. C. Rudolph. 1989. Red-cockaded woodpecker colony status and trends on the Angelina, Davy Crockett, and Sabine National Forests. U.S. Forest Service Research Paper SO-250.

Conner, R. N., and D. C. Rudolph. 1991. Forest habitat loss, fragmentation, and Red-cockaded Woodpecker populations. Wilson Bulletin 103:446-457.

Conner, R. N., D. C. Rudolph, and J. R. Walters. 2001. The red-cockaded woodpecker: survival in a fire-maintained ecosystem. University of Texas Press, Austin, Texas, USA.

Conroy, M. J., Y. Cohen, F. C. James, Y. G. Matsinos, and B. A. Maurer. 1995. Parameter estimation, reliability, and model improvement for spatially explicit models of animal populations. Ecological Applications 5:17-19.

Copeyon, C. K. 1990. A technique for constructing cavities for the red-cockaded woodpecker. Wildlife Society Bulletin 18:303-311.

Copeyon, C. K., J. R. Walters, and J. H. Carter, III. 1991. Induction of red-cockaded woodpecker group formation by artificial cavity construction. Journal of Wildlife Management 55:549-556.

Costa, R., and R. Escano. 1989. Red-cockaded woodpecker: status and management in the southern region in 1986. U.S. Forest Service Technical Publication R8-TP12.

Daniels, S. J. 1997. Female dispersal and inbreeding in the red-cockaded woodpecker. Thesis. Virginia Polytechnic Institute and State University, Blacksburg, Virginia, USA.

Daniels, S. J., and J. R. Walters. 2000. Natal dispersal and inbreeding in the Red-cockaded Woodpecker. Condor 102: 482-491.

DeFazio, J. T., Jr., M. A. Hunnicutt, M. R. Lennartz, G. L. Chapman, and J. A. Jackson. 1987. Red-cockaded woodpecker translocation experiments in South Carolina. Proceedings of the Annual Conference of the Southeastern Association of Fish and Wildlife Agencies 41:311-317.

DeLotelle, R. S., R. J. Epting, and G. Demuth. 1995. A 12year study of red-cockaded woodpeckers in central Florida. Pages 259-269 in D. L. Kulhavy, R. G. Hooper, and R. Costa, editors. Red-cockaded woodpecker: recovery, ecology and management. Center for Applied Studies in Forestry, College of Forestry, Stephen F. Austin State University, Nacogdoches, Texas, USA.

Doerr, P. D., J. R. Walters, and J. H. Carter, III. 1989. Reoccupation of abandoned clusters of cavity trees (colonies) by red-cockaded woodpeckers. Proceedings of the Annual Conference of the Southeastern Association of Fish and Wildlife Agencies 43:326-336.

Dunning, J. B., Jr., D. J. Stewart, B. J. Danielson, B. R. Noon, T. L. Root, R. H. Lamberson, and E. E. Stevens. 1995. Spatially explicit population models: current forms and future uses. Ecological Applications 5:3-11.

Franzreb, K. E. 1997. Success of intensive management of a critically imperiled population of Red-cockaded Wood- 
peckers in South Carolina. Journal of Field Ornithology 68:458-470

Heppell, S. S., J. R. Walters, and L. B. Crowder. 1994. Evaluating management alternatives for red-cockaded woodpeckers: a modeling approach. Journal of Wildlife Management 58:479-487.

Hooper, R. G. 1983. Colony formation by red-cockaded woodpeckers: hypotheses and management implications. Pages 72-77 in D. A. Wood, editor. Red-cockaded woodpecker Symposium II. Florida Game and Freshwater Fishery Commission and U.S. Fish and Wildlife Service, Atlanta, Georgia, USA.

Hooper, R. G., D. L. Krusac, and D. L. Carlson. 1991. An increase in a population of red-cockaded woodpeckers. Wildlife Society Bulletin 19:277-286.

Hooper, R. G., and C. J. McAdie. 1995. Hurricanes and the long-term management of the red-cockaded woodpecker. Pages 148-166 in D. L. Kulhavy, R. G. Hooper, and R. Costa, editors. Red-cockaded woodpecker: recovery, ecology and management. Center for Applied Studies in Forestry, College of Forestry, Stephen F. Austin State University, Nacogdoches, Texas, USA.

Hooper, R. G., J. C. Watson, and R. E. F. Escano. 1990. Hurricane Hugo's initial effects on red-cockaded woodpeckers in the Francis Marion National Forest. North American Wildlife and Natural Resources Conference 55:220224.

Jackson, J. A. 1994. Red-cockaded woodpecker (Picoides borealis). In A. Poole and F. Gill, editors. The birds of North America. Number 85. Academy of Natural Sciences, Philadelphia, Pennsylvania, and American Ornithologists' Union, Washington, D.C., USA.

James, F. C. 1995. The status of the red-cockaded woodpecker in 1990 and the prospect for recovery. Pages 439451 in D. L. Kulhavy, R. G. Hooper, and R. Costa, editors. Red-cockaded woodpecker: recovery, ecology and management. Center for Applied Studies in Forestry, College of Forestry, Stephen F. Austin State University, Nacogdoches, Texas, USA.

Judson, O. P. 1994. The rise of the individual-based model in ecology. Trends in Ecology and Evolution 9:9-14.

Kulhavy, D. L., R. G. Hooper, and R. Costa, editors. 1995. Red-cockaded woodpecker: recovery, ecology and management. Center for Applied Studies in Forestry, College of Forestry, Stephen F. Austin State University, Nacogdoches, Texas, USA.

Lacy, R. C., and T. W. Clark. 1990. Population viability assessment of the eastern barred bandicoot in Victoria. Pages 131-145 in T. W. Clark and J. H. Seebeck, editors. Management and conservation of small populations. Chicago Zoological Society, Chicago, Illinois, USA.

Lande, R. 1988. Genetics and demography in biological conservation. Science 241:1455-1460.

Lande, R. 1995. Mutation and conservation. Conservation Biology 9:782-791.

Lennartz, M., R. G. Hooper, and R. F. Harlow. 1987. Sociality and cooperative breeding of red-cockaded woodpeckers, Picoides borealis. Behavioral Ecology and Sociobiology 20:77-88.

Letcher, B. H., J. A. Priddy, J. R. Walters, and L. B. Crowder. 1998. An individual-based, spatially-explicit simulation model of the population dynamics of the endangered redcockaded woodpecker. Biological Conservation 86:1-14.

Ligon, J. D. 1970. Behavior and breeding biology of the Redcockaded Woodpecker. Auk 87:255-278.

Maguire, L. A., G. F. Wilhere, and Q. Dong. 1995. Population viability analysis for red-cockaded woodpeckers in the Georgia Piedmont. Journal of Wildlife Management 59: 533-542.

Mooij, W. M., and D. L. DeAngelis. 1999. Error propagation in spatially explicit models: a reassessment. Conservation Biology 13:930-933.

Murdoch, W. W., E. McCauley, R. M. Nisbet, S. C. Gurney, and A.M. de Roos. 1992. Individual-based models: combining testability and generality. Pages $18-35$ in D. L. DeAngelis and L. J. Gross, editors. Individual-based models and approaches in ecology: populations, communities, and ecosystems. Chapman and Hall, New York, New York, USA.

Reed, J. M., J. R. Walters, T. E. Emigh, and D. E. Seaman. 1993. Effective population size in red-cockaded woodpeckers: population and model differences. Conservation Biology 7:302-308.

Ruckelshaus, M., C. Hartway, and P. Kareiva. 1997. Assessing the data requirements of spatially explicit dispersal models. Conservation Biology 11:1298-1306.

Ruckelshaus, M., C. Hartway, and P. Kareiva. 1999. Dispersal and landscape errors in spatially explicit population models: a reply. Conservation Biology 13:1223-1224.

Rudolph, D. C., R. N. Conner, D. K. Carrie, and R. R. Shaefer. 1992. Experimental reintroduction of Red-cockaded Woodpeckers. Auk 109:914-916.

Ryan, M. R., B. G. Root, and P. M. Mayer. 1993. Status of piping plovers in the Great Plains of North America: a demographic simulation model. Conservation Biology 7: 581-585.

Shaffer, M. L. 1981. Minimum population sizes for species conservation. BioScience 31:131-134.

Shaffer, M. L. 1987. Minimum viable populations: coping with uncertainty. Pages 69-86 in M. E. Soulé, editor. Viable populations for conservation. Cambridge University Press, Cambridge, UK.

South, A. 1999. Dispersal in spatially explicit population models. Conservation Biology 13:1039-1046.

Thompson, R. L., editor. 1971. The ecology and management of the red-cockaded woodpecker. U.S. Department of Interior and Tall Timbers Research Station, Tallahassee, Florida, USA.

U.S. Army. 1996. 1996 management guidelines for the redcockaded woodpecker on Army installations. Unpublished report. Department of Defense, Department of the Army, Champaign, Illinois, USA.

USDA. 1995. Final environmental impact statement for the management of the red-cockaded woodpecker and its habitat on National Forests in the Southeast Region. Management Bulletin R8-MB 73, USDA Forest Service, Atlanta, Georgia, USA.

USFWS (U.S. Fish and Wildlife Service). 1985. Red-cockaded woodpecker recovery plan. U.S. Fish and Wildlife Service, Atlanta. Georgia, USA.

Vucetich, J. A., and S. Creel. 1999. Ecological interactions, social organization, and extinction risk in African wild dogs. Conservation Biology 13:1172-1182.

Vucetich, J. A., R. O. Peterson, and T. Waite. 1997. Effects of social structure and prey dynamics on extinction risk in gray wolves. Conservation Biology 11:957-965.

Walters, J. R. 1990. Red-cockaded woodpeckers: a "primitive" cooperative breeder. Pages 67-101 in P. B. Stacey and W. D. Koenig, editors. Cooperative breeding in birds: long-term studies of ecology and behavior. Cambridge University Press, Cambridge, UK.

Walters, J. R. 1991. Application of ecological principles to the management of endangered species: the case of the redcockaded woodpecker. Annual Review of Ecology and Systematics 22:505-523.

Walters, J. R., P. D. Doerr, and J. H. Carter, III. 1988. The cooperative breeding system of the red-cockaded woodpecker. Ethology 78:275-305.

Walters, J. R., P. D. Doerr, and J. H. Carter, III. 1992. Delayed dispersal and reproduction as a life history tactic in co- 
operative breeders: fitness calculations from red-cockaded woodpeckers. American Naturalist 139:623-643.

Watson, J. C., R. G. Hooper, D. L. Carlson, W. E. Taylor, and T. E. Milling. 1995. Restoration of the red-cockaded woodpecker population on the Francis Marion National Forest: three years post Hugo. Pages 172-182 in D. L. Kulhavy, R. G. Hooper, and R. Costa, editors. Red-cockaded woodpecker: recovery, ecology and management. Center for Applied Studies in Forestry, College of Forestry, Stephen F. Austin State University, Nacogdoches, Texas, USA.
Wennergren, U., M. Ruckelhaus, and P. Kareiva. 1995. The promise and limitations of spatial models in conservation biology. Oikos 74:349-356.

Wisdom, M. J., and L. S. Mills. 1997. Sensitivity analysis to guide population recovery: prairie-chickens as an example. Journal of Wildlife Management 61:302-312.

Wood, D. A., editor. 1983. Red-cockaded woodpecker symposium II. Florida Game and Freshwater Fishery Commission and U.S. Fish and Wildlife Service, Atlanta, Georgia, USA. 